\title{
Glimmers of hope: a global Green New Deal is feasible
}

\section{Journal Article}

Author(s):

Fesenfeld, Lukas P.

Publication date:

2021

Permanent link:

https://doi.org/10.3929/ethz-b-000514984

Rights / license:

Creative Commons Attribution 4.0 International

Originally published in:

GAIA - Ecological Perspectives for Science and Society 30(3), https://doi.org/10.14512/gaia.30.3.4 


\title{
Glimmers of hope: a global Green New Deal is feasible
}

\begin{abstract}
In light of limited international climate policy efforts, many are pessimistic about effective climate change mitigation. However, there is still a chance for a global Green New Deal which would reduce both socio-economic inequalities and greenhouse gas emissions. Unfolding feedbacks between technological, behavioral, and political changes provide an opportunity for transforming our societies. Yet, a Green New Deal in line with the green growth paradigm seems politically more feasible than a radical approach that rests upon a de-growth paradigm.
\end{abstract}

Lukas P. Fesenfeld (D)

Glimmers of hope: a global Green New Deal is feasible | GAIA 30/3 (2021): 150-155

Keywords: climate policy, Green New Deal, policy feedbacks, political feasibility, tipping points

S cientists, schoolchildren, and citizens around the world have joined the chorus demanding urgent climate action (Steffen et al. 2018, Lenton et al. 2019). Of particular concern is that interacting climate tipping points - such as permafrost thawing or the loss of the Amazon rainforest - could lead to irreversible and runaway climate change (Lenton et al. 2019). Global warming must not exceed $1.5^{\circ} \mathrm{C}$ to minimize such risks. To achieve this ambitious goal, we urgently need to mitigate both long-lived climate pollutants like carbon dioxide, but also powerful short-lived pollutants like methane (Fesenfeld et al. 2018). Irrespective of these undisputable risks, today's mitigation efforts fall short of what is needed to effectively prevent a climate catastrophe.

Social scientists have outlined several socio-technical hurdles that explain why human societies may fail to adequately deal with the existential risk of climate change, and eventually collapse. In the following, I will outline five prominent hurdles to ambitious climate mitigation, as discussed in the social sciences, and argue that, despite these hurdles, glimmers of hope and a unique window of opportunity exist for transforming our societies through a global Green New Deal (GND).

GND proposals typically have two defining features: 1 . a strong focus on governmental leadership aimed at changing public policies and increasing public investment, and 2. the goal of simultaneously reducing socio-economic inequalities and greenhouse gas emissions (Barbier 2019, Mastini et al. 2021, Jakob et al. 2020, Boyle et al. 2021).

Dr. Lukas P. Fesenfeld | University of Bern | Oeschger Centre for Climate Change Research | Hochschulstr. 4 | 3012 Bern | Switzerland and ETH Zurich | Institute of Science, Technology and Policy | Zurich | Switzerland | lukas.fesenfeld@unibe.ch

(C) 2021 L. P. Fesenfeld; licensee oekom verlag. This Open Access article is published under the terms of the Creative Commons Attribution License CCBY 4.0 (http://creativecommons.org/licenses/by/4.0).

https://doi.org/10.14512/gaia.30.3.4

Received January 16, 2021; revised version accepted July 28, 2021 (double-blind peer review)
Here, I claim that there are good reasons to believe that positive socio-technical tipping dynamics can enable the adoption of GNDs around the globe (Sharpe and Lenton 2021). There are not only climate tipping points (Lenton et al. 2019) that may trigger irreversible changes due to relatively small changes in the system, but also socio-technical ones that could accelerate the transformation of our societies (Farmer et al. 2019, Otto et al. 2020, Sharpe et al. 2021). In essence, feedback effects may not only create vicious, but also virtuous cycles of change, and such interactions within and between different socio-technical subsystems can lead to rapid transformation in line with meeting the $1.5^{\circ} \mathrm{C}$ target (Nyborg et al. 2016, Farmer et al. 2019, Fesenfeld 2020). In the following, I will outline why I am tentatively optimistic that such feedback effects can reduce social inequalities and greenhouse gas emissions and overcome key hurdles to ambitious climate mitigation.

\section{Overcoming key hurdles to ambitious climate change mitigation}

\section{Humans' short-term bias and discounting future climate risks and benefits}

A first key hurdle to adopting ambitious climate policies that social scientists have highlighted is humans' strong short-term bias, which makes them significantly discount potential future risks and benefits (Weber 2017, Bernauer 2013). This short-term bias is embedded in political and economic institutions (e.g., electoral cycles, company reporting standards) that tend to privilege short-term gains over long-term investment (Jacobs 2011).

However, I propose here that this hurdle is becoming less problematic for the adoption of ambitious climate policies than many suggest because the characterization and perception of climate change as a long-term problem is changing. Many citizens already perceive climate change as a serious problem today (Fes- 
enfeld and Rinscheid 2021), and the growing number of extreme weather events like wildfires, droughts, and storms are focusing media reporting on the real impacts of climate change and attracting public and stakeholder attention to the short-term costs and benefits of climate mitigation. Such events not only open a window of opportunity for societal movements (e.g., the Fridays for Future movement) to emerge and increase public pressure for ambitious climate policy, but also lead companies and investors around the world to recognize their risk and exposure to a changing climate. It is not surprising that one of the leading global rating companies, Moody's Corporation, recently purchased a data firm that measures the climate risk exposure of companies, cities, and states ${ }^{1}$. Also, the financial industry now seeks reliable quantification of climate risk exposure and puts pressure on its customers to consider those risks. Even powerful incumbent industries, like the agro-food industry, are starting to realize the near-term risks of climate change to the very core of their business models ${ }^{2}$. Moreover, citizens and stakeholders are not only starting to understand the near-term risks, but also the substantial short-term co-benefits of mitigating climate change - this in turn can increase policy support (Bain et al. 2016).

From this evidence, some recommendations follow: researchers and consultants can amplify the probability of industries and investors understanding near-term climate change risks that affect them and the direct co-benefits of climate mitigation. For the adoption of ambitious GNDs, it is essential that policymakers and communicators create a "positive climate policy narrative" that stresses both short-term climate risks and co-benefits.

\section{Blame avoidance and risk of public backlash}

A second hurdle is the fact that many politicians tend to focus on avoiding public blame and reducing the political risks of costly but effective mitigation. Decision-makers often believe that citizens are not willing to pay the price for effective mitigation (Hertel-Fernandez et al. 2019). What is more, many citizens seem to have similar beliefs, and perceive other members of society to be unsupportive of investment into effective mitigation (Mildenberger and Tingley 2017). Political polarization, distrust in science, and populism are on the rise and some people have raised serious doubts about the scientific consensus concerning the severity of climate change and human responsibility for it (Huber et al. 2020).

Despite this, the last few years have shown that politicians do not necessarily need to be overly concerned about public backlash against ambitious climate mitigation. Green parties around the world have gained political momentum and recent survey research shows that in countries that are major economic actors
- like the USA, China, India, Germany, South Africa, and the United Kingdom - a majority of citizens support climate policies with perceptible mitigation costs, for example, policies that significantly increase the price of emission-intensive goods like fossil fuels or meat products (Beiser-McGrath and Bernauer 2019, Fesenfeld et al. 2020, Wicki et al. 2019). These survey results are buttressed by real-world election outcomes. ${ }^{3}$

Several policy recommendations can be derived from this: First, to generate public support, policymakers should not hide policy costs but communicate to citizens that they are taking their interests seriously, designing policies in a socially fair way, and should explain to people the rationale for adopting ambitious climate policies by creating a "positive climate policy narrative" (Fesenfeld et al. 2021). Second, policymakers should propose effective and feasible climate policy packages that bundle ambitious mitigation measures with policies that compensate mitigation costs for citizens by including clear benefits for them, and increase the perceived fairness of such policies (Fesenfeld et al. 2020, Wicki et al. 2019). Credible consideration of fairness principles in policy design can effectively reduce the risks of public backlash (Klenert et al. 2018, Beiser-McGrath and Bernauer 2019). ${ }^{4}$

Bundling social, economic, and climate policies into GND packages that foster job growth in cleaner industries (e.g., the renewable energy industry), increasing social security, and fostering mitigation efforts can help to build broad public support and the popularity of the former among politicians - especially during the COVID-19 crisis (Bergquist et al. 2020). Low interest rates and increasing revenues from carbon taxation also provide governments with the unique opportunity to finance such ambitious GND packages. Third, particularly in the USA, the experience of extreme political polarization and populism is likely to have altered the belief of leading politicians and lobbyists that the cost of political instability is larger than the cost of introducing a GND. While distrust of the scientific consensus about climate change, populism, and political polarization can be hurdles to effective mitigation, in most countries around the world the vast majority of citizens believe in the reality of human-caused climate change (Steg 2018). In essence, policymakers can credibly communicate they are acting in the interest of citizens when they adopt an ambitious GND (Huber et al. 2020, Fesenfeld et al. 2021).

\section{Collective action problems}

The third key hurdle is that powerful incumbent industries show little interest in bearing the cost of mitigation if it is associated with uncertain benefits for themselves. Collective action theory predicts that strong lobby groups of fossil fuel and other pollutant industries prevent effective mitigation because of their ho-

1 https://www.nytimes.com/2019/07/24/climate/moodys-ratings-climate-change-data.html

2 http://blogs.edf.org/growingreturns/2020/09/09/finance-markets-climate-risk-report-agriculture

3 For example, in Germany the Green Party has recently achieved historic election results in some federal states and is on its way to becoming part of the next federal government. Moreover, in the strongly polarized political context of the USA, President Biden was elected despite - and partially because of the fact he ran on a pro-climate policy platform.

4 For example, the progressive design of the carbon tax in Canada means that tax revenue is redistributed back to citizens and around $80 \%$ of households particularly low-income households - receive more in transfers than they pay in direct and indirect costs. 
mogenous interests and significant conflict capacity (for example, Bernauer 2013).

However, while I do not contest the basic premises of collective action theory, I argue that its implications for climate policymaking have to be reconsidered. Although powerful incumbent industries, like the meat and coal industry, have long been wellorganized opponents of ambitious climate policy, the situation for at least some of those players has changed dramatically. Not only are powerful industries recognizing the short-term costs and benefits of mitigation, but they also have an increasingly diversified portfolio of products, including clean technologies, to deploy 5 .

Portfolio diversification lessens companies' inclination to engage in conflict in relation to lobbying against ambitious climate policies. In fact, portfolio diversification leads to ambiguous lobbying strategies. In this sense, the predictions made by collective action theory can work in favor of a GND. International competition from new market players like Tesla in the automotive industry or Beyond Meat in the food industry are increasingly changing the odds in favor of incumbent actors supporting ambitious climate policies. pear unfair, yet realistically, in light of the enormous social cost of a further delay in effective mitigation, but the good news is that both the public and front-running green industry players are willing to bear some transition costs and to compensate losers (Fesenfeld et al. 2020, Wicki et al. 2019, Rinscheid and Wüstenhagen 2019, Beiser-McGrath and Bernauer 2019).

\section{Free-riding risks}

The fourth hurdle to ambitious climate policies, which receives prominent attention in social science literature, is based on global public goods theory. This theory forecasts that successful international cooperation for mitigation is difficult to achieve, given that actors have the incentive to free-ride on the mitigation efforts of others (Nordhaus 2015, Bernauer 2013).

However, empirical evidence for this argument is contested and indicates that it is domestic distributional conflict rather than international free-riding concerns that determine national climate policy ambitions (Aklin and Mildenberger 2020). Local and national climate mitigation co-benefits and increasing positive returns from climate mitigation might also reduce the free-rider problem (Hale 2020). Moreover, the "climate club" literature

\section{Bundling social, economic, and climate policies into Green New Deal packages that foster job growth in cleaner industries which will increase social security and foster climate change mitigation efforts, can help to build broad public support and popularity among politicians, especially during the COVID-19 crisis.}

Several policy recommendations follow from this: first, smart policy design and sequencing can foster technological innovation and the development of new and powerful industry players that destroy existing markets and challenge incumbent industries to switch to cleaner technologies and support ambitious policies (Meckling et al. 2015). These new industry players are also likely to recognize the need to design climate policies that benefit themselves economically in a socially acceptable and fair way to earn broad public support. This, in turn, increases the odds of the introduction of GND policies that include some (perhaps limited) redistribution and welfare state components.

Moreover, researchers and climate policy advocates can broker the exchange between progressive companies and incumbent actors, and thereby help to reduce the coordination costs associated with the build-up of successful coalitions that support GNDs. The Olson theorem of collective action predicts that consumers and citizens will have to pay at least some price for the pollution caused by well-organized companies (Bernauer 2013). Normatively speaking, proponents of a GND will most likely have to take on some of the transition costs themselves, and defer the rest to future generations (e.g., via green bonds). This might ap- suggests a way out of potential global public goods and free-rider dilemmas (Hovi et al. 2019, Nordhaus 2015, Keohane and Victor 2016). While there are visible climate clubs at the urban, state, and company level (for instance, the US Climate Alliance ${ }^{6}$ ), it is likely that in the near term more influential country climate clubs with ambitious mitigation goals will emerge due to the bottomup designed framework of the Paris Agreement. In other words, powerful (multinational) companies, investor coalitions, and governments will start to realize the unique market opportunities involved in positioning themselves as frontrunners in a low-emission economy and commit themselves to higher industry standards and ambitious pollution regulations. The European Commission proposal for a so-called European Green Deal, which is primarily a green growth and industry program, indicates the political momentum of industrial green policy. While the European Green Deal aims at a socially equitable transition process for example, through its "just transition mechanism" that seeks to mobilize at least 100 billion Euro in investment to support workers and citizens in the regions most impacted by the decarbonisation transition - its primary focus is on boosting growth in clean technology sectors. The 2020 promise of the Chinese

5 https://www.cleanenergywire.org/news/european-energy-companies-invest-one-trillion-euros-renewables-2030

6 http://www.usclimatealliance.org 
government to become carbon neutral by 2060 and the climate policy plans of the Biden administration in the USA also point in the same direction.

Ratcheting-up and spillover processes for non-club members can take place once a club reaches a critical size; for instance, in terms of markets covered and trading volumes. In essence, conditional commitments and club goods, such as preferential trade agreements, investment, access to research funding, and emis- sil fuel assets and potentially large investment losses (Mercure et al. 2018). The risk of losing vast assets as well as public pressure has inspired a growing divestment movement that includes important institutional investors such as the Norwegian state fund. In turn, this outlook is motivating an increasing number of companies, but also governments (even in fossil-fuel-dependent countries like Australia, Poland, and Saudi Arabia) to start rethinking their business models, investments, and industrial

\section{There are no strong coalitions for more radical Green New Deal proposals that aim at restructuring political and economic systems.}

sions trading schemes can increase other countries' willingness to contribute (Hovi et al. 2019). ${ }^{7}$ One policy insight is thus that it might be possible to accelerate climate policy, related social norms, and clean technology diffusion even without the presence of a strong club if either China, the USA, or the EU take credible unilateral steps towards transitioning to a climate-neutral society.

\section{Carbon lock-ins}

The fifth key hurdle are institutional carbon lock-ins that inhibit rapid system transformation (Unruh 2000). The coevolution of encultured habits and norms with path-dependent technologies and infrastructures makes it difficult to change institutions and escape the inertia entrenched in systems. This in turn privileges incumbent actors that oppose effective mitigation (see hurdle 3); they can leverage their privileged positions in existing socio-technical systems and use all available resources to stop the transition and ambitious climate policies (Geels et al. 2017).

While carbon lock-ins and socio-technical path dependencies may slow down the transition process, we are likely to have already entered an acceleration phase in the transition of key sectors, like the energy system (Markard 2018). While fossil-fuel related emissions are currently rebounding in light of the postpandemic economic recovery, renewable energies are diffusing rapidly, and in recent years the levelized cost of electricity from renewable energy sources has dropped significantly. In many countries today, electricity based on renewable energy is already cheaper than fossil-fuel-based electricity, indicating the irreversible passing of a socio-technical tipping point (figure 1, p. 154).

In 2019, global electricity production from coal decreased by around $3 \%$ (while in the EU and North America coal demand drops by even $15 \%$ ), the largest drop on record by far. In 2020 , the International Energy Agency expects an even stronger decline in fossil fuel use and production due to the sudden shock of COVID-19 (e.g., global coal demand is expected to fall by $8 \%$. This is an example of what some investors and analysts denote the "carbon bubble", which might lead to massive stranded fos- policies. Although perhaps the single most important global player in relation to achieving the $1.5^{\circ} \mathrm{C}$ target, China, is still investing and building coal-fired plants, there are reasons to believe that many of these coal plants will not be utilized on the grid? Moreover, China is already the global leader in the production of solar cells, wind turbines, energy-saving lights, and solar water heaters, and the potential future frontrunner in electric and fuel-efficient cars as well as battery technology (Barbier 2019).

In some sectors (e.g., energy and transport systems), we are now experiencing the more complex interaction of multiple new technologies that have matured over the last decades and a rapid decay of traditional business models and technologies (Markard 2018). The interaction between different technological innovations (e.g., rapid cost reductions in lithium-ion batteries, wind, and solar energy) within and across sectors (e.g., cheaper renewable energy and lower production costs for electric vehicles) helps break up existing path dependencies and accelerate the low-carbon transition (Markard 2018, Geels et al. 2017). Policy-induced technological learning has led to the rapid diffusion of clean technologies (Schmidt and Sewerin 2017). Low financing costs and interest rates create favorable conditions for low-emission technology investment (Egli et al. 2018) and open an important window of opportunity for adopting a GND. While the transition in some sectors, like the food and transport systems, depends heavily on the interaction of technological and behavioral changes, research shows that policies can trigger tipping points and induce a rapid co-evolutionary change of norms, behaviors, and technologies (Nyborg et al. 2016, Sharpe et al. 2021, Fesenfeld 2020).

An important policy recommendation for countering lockin effects is thus simultaneously investing into cleaner technologies and fostering the adoption of the latter innovations. This can create viable niche markets and trigger positive tipping point dynamics that make it possible to adopt exnovation-oriented policies aimed at phasing out carbon intensive infrastructure, technology, and behavior.

7 Studies show that such clubs can even be successful without the participation of large countries like the USA (Hovi et al. 2019).

8 https://www.iea.org/reports/global-energy-review-2020/coal

9 https://www.wired.com/story/china-is-still-building-an-insane-number-of-new-coal-plants 


\section{Concluding remarks and outlook}

There are glimmers of hope: while critical hurdles to a rapid transformation of our societies in line with the climate change targets of the Paris Agreement are still in place, and many post-pandemic recovery packages do not foster the transition to a net-zero economy (Carbon Brief 2021), there are good reasons to believe that dynamic feedback effects within and between different socio-technical subsystems can make a global Green New Deal feasible. The political and economic risks of adopting ambitious climate policies combined with social and welfare state policies are now smaller, and the associated opportunities larger than ever before. Spillover effects, competition, and club systems can help to spread GND policies across countries. However, the design and ambition level of GND proposals are likely to determine the speed and success of their global diffusion. Some proposals build on the premise that "green growth" can lead to a decoupling of greenhouse gas emissions from well-being and a reduction in socio-economic inequality. In contrast, other proposals are embedded into a "de-growth" narrative and argue for a fundamental change in political and economic foundations that reduces inequality and leads to the achievement of the Paris targets (Wiedmann et al. 2020, Jakob et al. 2020, Mastini et al. 2021).

While the evidence and policy recommendations presented in this article suggest that less radical GND proposals, in line with the green growth paradigm, are politically feasible, it is less likely that more radical GND proposals in line with the de-growth paradigm will attract sufficient political support across the globe. Less radical GND proposals do not question the prevailing economic growth paradigm per se, and offer increasing benefits to a limited number of political and economic stakeholders. In contrast, there are no strong coalitions for more radical GND proposals that aim at fundamentally restructuring political and economic systems. Today, the implementation of such more radical proposals is thus an unrealistic scenario.

Further research is necessary to evaluate if less radical GND proposals will suffice for achieving the Paris targets, particularly in the light of the post-pandemic rise in greenhouse gas emissions and the rapid destruction of globally critical ecosystems like the Amazon rainforest that can lead to dangerous climate tipping points in the near term. Researchers should also support decision-makers in business, civil society, and politics to better understand climate-related risks and opportunities, to identify politically feasible transition pathways, to create a positive climate policy narrative, and to design the fair and effective policy packages that are needed to accelerate the transformation to net-zero societies.

I would like to thank two anonymous reviewers for their helpful comments. Moreover, I would like to thank my colleagues at ETH Zurich, at the University of Bern, and at the University of St. Gallen for their valuable feedback.

FIGURE 1: The diffusion of clean technologies, such as photovoltaics, across sectors does not only help to better link cross-sectorial climate change mitigation efforts but also to enable the growth of new winning coalitions that support more holistic Green New Deal proposals. The photograph shows a ground-mounted photovoltaic system combined with sheep farming.

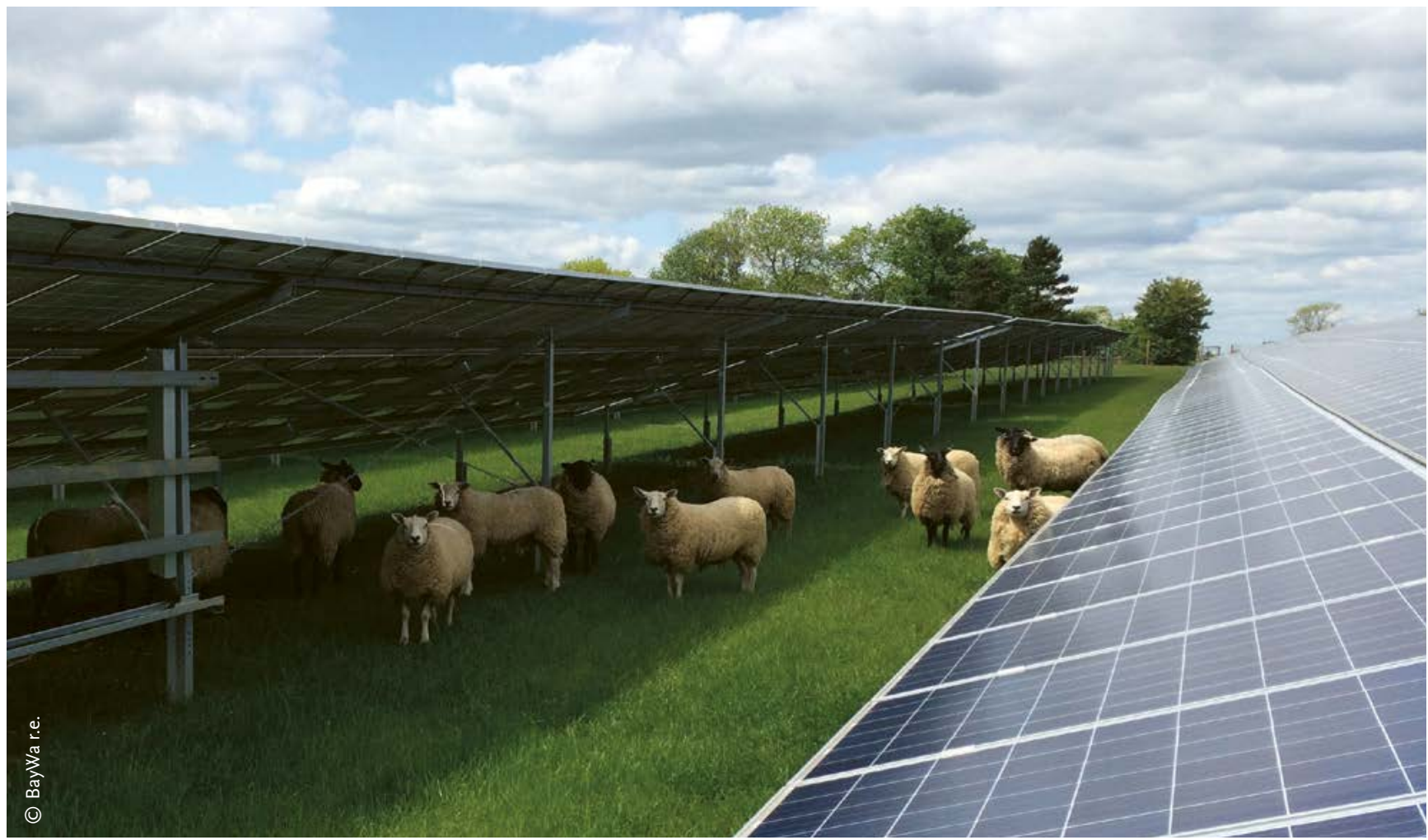




\section{References}

Aklin, M., M. Mildenberger. 2020. Why distributive conflict, not collective action, characterizes the politics of climate change. Global Environmental Politics 20/4: 4-26. https://doi.org/10.1162/glep_a_00578.

Bain, P. G. et al. 2016. Co-benefits of addressing climate change can motivate action around the world. Nature Climate Change 6/2: 154-157. https://doi.org/10.1038/nclimate2814.

Barbier, E. B. 2019. How to make the next green new deal work. Nature 565: 6.

Beiser-McGrath, L. F., T. Bernauer. 2019. Could revenue recycling make effective carbon taxation politically feasible? Science Advances 5/9: aax3323. https://doi.org/10.1126/sciadv.aax3323.

Bergquist, P., M. Mildenberger, L. Stokes. 2020. Combining climate, economic, and social policy builds public support for climate action in the US. Environmental Research Letters 15/5: 54019. https://doi.org/10.1088/1748-9326/ab81c1.

Bernauer, T. 2013. Climate change politics. Annual Review of Political Science 16: 421 -448. https://doi.org/10.1146/annurev-polisci-062011-154926.

Boyle, A. D., G. Leggat, L. Morikawa, Y. Pappas, J. C. Stephens. 2021. Green new deal proposals: Comparing emerging transformational climate policies at multiple scales. Energy Research and Social Science 81/11: 102259. https://doi.org/10.1016/J.ERSS.2021.102259.

Carbon Brief. 2021. Coronavirus: Tracking how the world's "green recovery" plans aim to cut emission. https://www.carbonbrief.org/coronavirus-trackinghow-the-worlds-green-recovery-plans-aim-to-cut-emissions (accessed May 7, 2021).

Egli, F., B. Steffen, T. Schmidt. 2018. A dynamic analysis of financing conditions for renewable energy technologies. Nature Energy 3/12: 1084-1092. https://doi.org/10.1038/s41560-018-0277-y.

Farmer, J. D. et al. 2019. Sensitive intervention points in the post-carbon transition. Science 364/6436: 132-134. https://doi.org/10.1126/science.aaw7287.

Fesenfeld, L. P. 2020. The political feasibility of transformative climate policy: Public opinion about transforming food and transport Systems. Zurich: ETH Zurich. https://doi.org/10.3929/ethz-b-000425564.

Fesenfeld, L. P., A. Rinscheid. 2021. Emphasizing urgency of climate change is insufficient to increase policy support. One Earth 4/3: 411-424. https://doi.org/10.1016/j.oneear.2021.02.010.

Fesenfeld, L. P., T. S. Schmidt, A. Schrode. 2018. Climate policy for short- and long-lived pollutants. Nature Climate Change 8: 933-936. https://doi.org/10.1038/s41558-018-0328-1.

Fesenfeld, L. P., Y. Sun, M. Wicki, T. Bernauer. 2021. The role and limits of strategic framing for promoting sustainable consumption and policy. Global Environmental Change 68/05:102266. https://doi.org/10.1016/j.gloenvcha.2021.102266.

Fesenfeld, L.P., M. Wicki, Y. Sun, T. Bernauer. 2020. Policy packaging can make food system transformation feasible. Nature Food 1/3: 173-182. https://doi.org/10.1038/s43016-020-0047-4.

Geels, F. W, B. K. Sovacool, T. Schwanen, S. Sorrell. 2017. Sociotechnical transitions for deep decarbonization. Science 357/6357: 1242-1244. https://doi.org/10.1126/science.aao3760.

Hale, T. 2020. Catalytic cooperation. Global Environmental Politics 20/4: 73-98. https://doi.org/10.1162/glep_a_00561.

Hertel-Fernandez, A., M. Mildenberger, L. C. Stokes. 2019. Legislative staff and representation in congress. American Political Science Review 113/1: 1 -18. https://doi.org/10.1017/S0003055418000606.

Hovi, J., D. F. Sprinz, H. Sælen, A. Underdal. 2019. The club approach: A gateway to effective climate co-operation? British Journal of Political Science 49/3: 1071-1096. https://doi.org/10.1017/S0007123416000788.

Huber, R. A., L.P. Fesenfeld, T. Bernauer. 2020. Political populism, responsiveness, and public support for climate mitigation. Climate Policy 20/3: 373 -386. https://doi.org/10.1080/14693062.2020.1736490.

Jacobs, A. M. 2011. Governing for the long term: Democracy and the politics of investment. Cambridge, UK: Cambridge University Press.

Jakob, M., W. F. Lamb, J. C. Steckel, C. Flachsland, O. Edenhofer. 2020. Understanding different perspectives on economic growth and climate policy. Wiley Interdisciplinary Reviews: Climate Change 11/6: 1-17. https://doi.org/10.1002/wcc.677.
Keohane, R. O., D. G. Victor. 2016. Cooperation and discord in global climate policy. Nature Climate Change 6: 570-575. https://doi.org/10.1038/nclimate2937.

Klenert, D. et al. 2018. Making carbon pricing work for citizens. Nature Climate Change 8: 669-677. https://doi.org/10.1038/s41558-018-0201-2.

Lenton, T. M. et al. 2019. Climate tipping points - too risky to bet against. Nature 575: 592-595. https://doi.org/10.1038/d41586-019-03595-0.

Markard, J. 2018. The next phase of the energy transition and its implications for research and policy. Nature Energy 3/8: 628-633. https://doi.org/10.1038/s41560-018-0171-7.

Mastini, R., G. Kallis, J. Hickel. 2021. A green new deal without growth? Ecological Economics 179/11: 106832. https://doi.org/10.1016/j.ecolecon.2020.106832.

Meckling, J., N. Kelsey, E. Biber, J. Zysman. 2015. Winning coalitions for climate policy. Science 349: 1170-1171. https://doi.org/10.1126/science.aab1336.

Mercure, J. F. et al. 2018. Macroeconomic impact of stranded fossil fuel assets. Nature Climate Change 8/7: 588-593. https://doi.org/10.1038/s41558-018-0182-1.

Mildenberger, M., D. Tingley. 2017. Beliefs about climate beliefs: the importance of second-order opinions for climate politics. British Journal of Political Science 49/4: 1279-1307. https://doi.org/10.1017/S0007123417000321.

Nordhaus, W. 2015. Climate Clubs: Overcoming free-riding in international climate policy. American Economic Review 105/4: 1339-1370. http://dx.doi.org/10.1257/aer.15000001.

Nyborg, K. et al. 2016. Social norms as solutions. Science 354/6308: 42-43. https://doi.org/10.1126/science.aaf8317.

Otto, I. M. et al. 2020. Social tipping dynamics for stabilizing earth's climate by 2050. Proceedings of the National Academy of Sciences 117/5: 2354-2365. https://doi.org/https://doi.org/10.1073/pnas.1900577117.

Rinscheid, A., R. Wüstenhagen. 2019. Germany's decision to phase out coal by 2038 lags behind citizens' timing preferences. Nature Energy 4/10: 856-863. https://doi.org/10.1038/s41560-019-0460-9.

Schmidt, T. S., S. Sewerin. 2017. Technology as a driver of climate and energy politics. Nature Energy 2/6: 170-184. https://doi.org/10.1038/nenergy.2017.84.

Sharpe, S., T. M. Lenton. 2021. Upward-scaling tipping cascades to meet climate goals: Plausible grounds for hope. Climate Policy 21/4: 421-433. https://doi.org/10.1080/14693062.2020.1870097.

Steffen, W. et al. 2018. Trajectories of the earth system in the anthropocene. Proceedings of the National Academy of Sciences 115/33: 8252-8259. https://doi.org/10.1073/pnas.1810141115.

Steg, L. 2018. Limiting climate change requires research on climate action. Nature Climate Change 8/9: 759-761. https://doi.org/10.1038/s41558-018-0269-8.

Unruh, G. C. 2000. Understanding carbon lock-in. Energy Policy 28/12: 817-830. https://doi.org/10.1016/S0301-4215(00)00070-7.

Weber, E.U. 2017. Breaking cognitive barriers to a sustainable future. Nature Human Behaviour 1: 0013. https://doi.org/10.1038/s41562-016-0013.

Wicki, M., L. P. Fesenfeld, T. Bernauer. 2019. In search of politically feasible policy packages for sustainable transport: Insights from choice experiments in China, Germany, and the USA. Environmental Research Letters 14/8: 084048. https://doi.org/10.1088/1748-9326/ab30a2.

Wiedmann, T., M. Lenzen, L. T. Keyßer, J. K. Steinberger. 2020. Scientists' warning on affluence. Nature Communications 11/1: 1-10. https://doi.org/10.1038/s41467-020-16941-y.

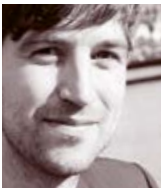

\section{Lukas P. Fesenfeld}

Studies in public policy. $\mathrm{PhD}$ in political economy and environmental governance. Since 2020 senior researcher at the Institute of Political Science and the Oeschger Centre for Climate Change Research at the University of Bern, Switzerland. Lecturer at ETH Zurich, Switzerland. Founding director of $N A H$ haft Institute for Sustainable Food Strategies. Research interests: political economy of food and meat system transformation, climate governance, political psychology. 